\title{
Heterotrimeric G-protein alpha-12 (G'12) subunit promotes oral cancer metastasis
}

\author{
Chai Phei Gan ${ }^{1}$, Vyomesh Patel ${ }^{1,2}$, Constantinos M. Mikelis², Rosnah Binti Zain ${ }^{3,4}$, \\ Alfredo A. Molinolo², Mannil Thomas Abraham ${ }^{5}$, Soo-Hwang Teo $^{1}$, Zainal Ariff \\ Abdul Rahman ${ }^{3}$, J. Silvio Gutkind ${ }^{2}$, Sok Ching Cheong ${ }^{1,3}$ \\ ${ }^{1}$ Oral Cancer Research Team, Cancer Research Initiatives Foundation (CARIF), Selangor, Malaysia \\ ${ }^{2}$ Oral and Pharyngeal Cancer Branch, National Institutes of Dental and Craniofacial Research, National Institutes of Health, \\ Bethesda, USA \\ ${ }^{3}$ Department of Oro-Maxillofacial Surgical and Medical Sciences, Faculty of Dentistry, University of Malaya, Kuala Lumpur, \\ Malaysia \\ ${ }^{4}$ Oral Cancer Research and Coordinating Centre (OCRCC), University of Malaya, Kuala Lumpur, Malaysia \\ ${ }^{5}$ Department of Oral and Maxillofacial Surgery, Tengku Ampuan Rahimah Hospital, Klang, Malaysia \\ Correspondence to: \\ Sok Ching Cheong, e-mail: sokching.cheong@carif.com.my \\ Keywords: Oral squamous cell carcinoma, G-protein alpha-12, Lymph node, Metastasis \\ Received: June 23, $2014 \quad$ Accepted: September 04, $2014 \quad$ Published: November 12, 2014
}

\section{ABSTRACT}

Oral squamous cell carcinoma (OSCC) has a propensity to spread to the cervical lymph nodes (LN). The presence of cervical LN metastases severely impacts patient survival, whereby the two-year survival for oral cancer patients with involved LN is $\sim \mathbf{3 0} \%$ compared to over $\mathbf{8 0} \%$ in patients with non-involved LN. Elucidation of key molecular mechanisms underlying OSCC metastasis may afford an opportunity to target specific genes, to prevent the spread of OSCC and to improve patient survival. In this study, we demonstrated that expression of the heterotrimeric G-protein alpha-12 (G 12) is highly up-regulated in primary tumors and LN of OSCC patients, as assessed by quantitative polymerase chain reaction (qPCR) and immunohistochemistry (IHC). We also found that exogenous expression of the constitutively activated-form of G 12 promoted cell migration and invasion in OSCC cell lines. Correspondingly, inhibition of G 12 expression by shRNA consistently inhibited OSCC cell migration and invasion in vitro. Further, the inhibition of $\mathbf{G 1 2}$ signaling by regulator of G-protein signaling (RGS) inhibited G 12-mediated RhoA activation, which in turn resulted in reduced LN metastases in a tongue-orthotopic xenograft mouse model of oral cancer. This study provides a rationale for future development and evaluation of drug candidates targeting G'12-related pathways for metastasis prevention.

\section{INTRODUCTION}

Cancer metastasis is a major hurdle for cancer treatment as it adversely impacts the quality of life and patient survival [1]. Oral squamous cell carcinoma (OSCC) predominantly spreads via the lymphatic route, and primarily to the cervical lymph nodes (LN). The presence of cervical LN metastases remains the most significant prognostic indicator in OSCC patients [2-4]. The two-year survival for OSCC patients with LN metastasis is $\sim 30 \%$ compared to $80 \%$ for those without $\mathrm{LN}$ metastasis [5]. Therefore, the elucidation of key molecular mechanisms involving OSCC spread from their primary site affords an excellent opportunity to target these genes to prevent and stop the spread of OSCC and to improve patient survival.

Ga12 and Ga13 are members of the G12 subfamily of heterotrimeric G-proteins [6]. Activation of the G12 subfamily regulates a wide variety of important cellular events and responses that range from embryonic development [7-9], platelet activation [10, 11], angiogenesis [12], to apoptosis [13]. Most notably, 


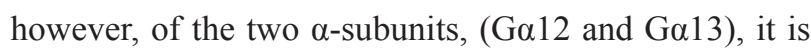
$\mathrm{G} \alpha 12$ that has consistently been demonstrated to play a key role in cancer development and progression, largely due to its potency in oncogenic transformation $[14,15]$.

There is now compelling evidence that Ga12 promotes cancer metastasis [16-19]. We have previously reported that Ga12 was significantly up-regulated in OSCC biopsies when compared to normal oral mucosa regardless of risk habits of the patients [20]. In this study, we sought to further investigate the functional impact of Ga12 up-regulation on OSCC development and progression. From our emerging data, we demonstrated that inhibiting G12 signaling results in reduced OSCC metastasis to $\mathrm{LN}$, thereby identifying a potential therapeutic target to prevent the spread of OSCC and a range of other malignancies.

\section{RESULTS}

\section{Ga12 is up-regulated in OSCC}

Previously, we reported that Ga12 mRNA levels were up-regulated by more than two-fold in OSCC [20]. In this study, we sought to further validate these observations in an independent set of specimens and to assess if high levels of G $\alpha 12$ were likely to have a biological impact on tumor progression. Firstly, as Ga12 share 67\% sequence similarity with Ga13 [6], we examined mRNA levels of both molecules from the same tissue sample set. We confirmed that Ga12 mRNA levels were significantly up-regulated in OSCC $(p=0.014)$, compared to Ga13 levels, which were essentially unchanged between OSCC and NOM tissues (Figure 1A). Furthermore, we found that the majority of OSCC tissues $(26 / 47 ; 55.3 \%)$ had mRNA levels of Ga12 that were elevated $\geq 2$ fold, further indicating the overexpression of $\mathrm{G} \alpha 12$ in this cancer type (Figure 1B). Consistently, IHC analysis demonstrated that the protein levels of Ga12 were overexpressed in OSCC tissues and tumor cells that have spread to the LN, but not in the NOM tissues (Figure 1C). In particular, Ga12 protein was significantly overexpressed in 34 of 43 (79.1\%) OSCC cases and majority of these have the intensity score of 2 or 3 thus confirming our prior observations (Figure 1D). In contrast, 22 of $23(95.7 \%)$ of NOM tissues showed low levels of Ga12 (intensity score 0-1). Although Ga12 was differentially expressed between OSCC and NOM, Ga12 was not associated with any of the clinical parameters, as detailed in Table 1. We next examined $\mathrm{G} \alpha 12$ protein levels in $12 \mathrm{LN}$ positive tissues that were matched to the primary tumors from the same patient, and found that 10 of 12 patient samples $(83.3 \%)$ had $\mathrm{G} \alpha 12$ overexpression in tumor cells that had metastasized to the cervical LN. Overall, Ga12 staining intensity was essentially similar between primary tumors and the matched LNs in majority of the cases (7/12), indicating that the high levels of Ga12 is retained in both primary tumors and LN metastasis, and 3/12 (25\%) cases had increased Ga12 levels in the LN compared to the primary tumor (Figure 1E). However 1/12 showed consistently low expression of Ga12 in both the primary tumor and LN, while the remaining one case, showed high Ga12 levels in the primary but low in the matched LN. For potential detailed functional analysis of these observations, we next assessed the protein levels of $\mathrm{G} \alpha 12$ in a panel of OSCC cell lines previously established in our laboratory. From our data, we found that Ga12 was consistently overexpressed in the OSCC cell lines but not in normal oral keratinocytes primary cultures (ORL218 and ORL232; Figure 1F). In particular, 4 OSCC cell lines (ORL48, ORL174, ORL188 and ORL214) had the highest $\mathrm{G} \alpha 12$ expression with reference to the HeLa cells transduced to overexpress $\mathrm{G} \alpha 12$.

\section{Activation and expression of Ga12 promotes OSCC cell migration and invasion}

From our previous data, we chose ORL150 cells, largely due to the lower Ga12 levels amongst the OSCC cell lines examined, to ectopically overexpress

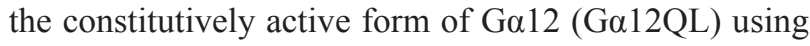
pLXRN retrovirus transduction. Exogenous expression of Ga12QL in ORL150 stimulated Ga12 signaling, as indicated by the activation of down-stream RhoA (supplementary Figure 1). We next determined if this Ga12 activation was going to have an effect on cell migration. As seen in the scratch assay, we observed that the open wound area was $56.3 \%$ in ORL150/G $\alpha 12 \mathrm{QL}$ cells when compared to $85.7 \%$ in the vector control (VC) cells after 18 hours, indicating that expression of Ga12QL significantly increased the rate of migration of ORL150 cells in closing the open wound area ( $<<0.001$; Figure 2A). Further, the transwell invasion assay demonstrated that ORL150/Ga12QL cells had a significant increase in the number of cells invading through the matrigel barrier in response to NIH3T3 cell-conditioned medium, compared to the $\mathrm{VC}$ cells (Figure 2B).

Previous work has reported that both $\mathrm{G} \alpha 12$ and Ga13 of the G12 sub-family promote Rho activation by binding to the regulator of G-protein signaling (RGS) domain of RGS-containing Rho guanine nucleotide exchange factors (GEFs) [19, 21]. Here, we sought to inhibit both $\mathrm{G} \alpha 12$ and Ga13 signaling in OSCC by expressing a chimeric molecule consisting of GFP fused to the RGS domain of PDZ-RhoGEF in ORL48 cells (ORL48/RGS) (Supplementary Figure 2). ORL48 cells were used for these studies due to high endogenous levels of $\mathrm{G} \alpha 12$ protein as well as the ability to form tumors when xenografted in mice. Expression of the chimeric molecule did not alter the endogenous levels of total 


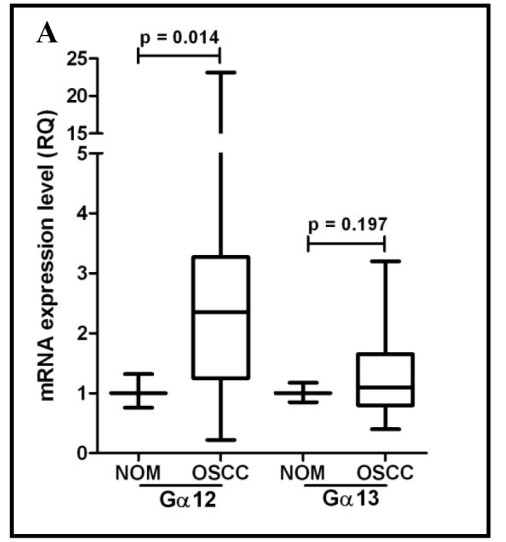

C
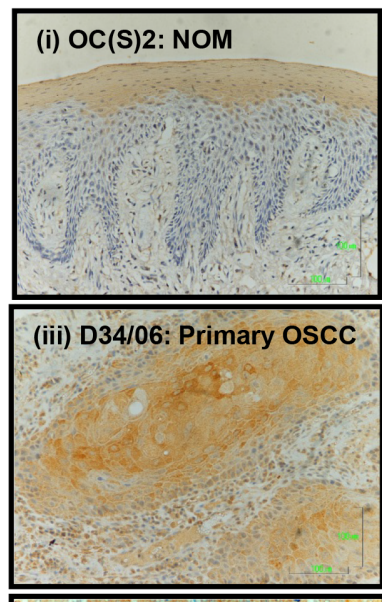

(v): D498106: Primary OSCC

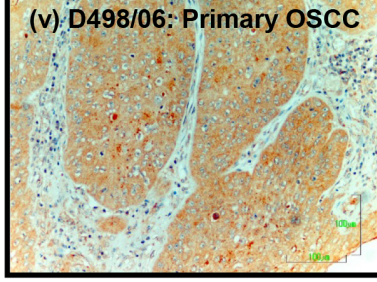

(ii) D533/05: NOM

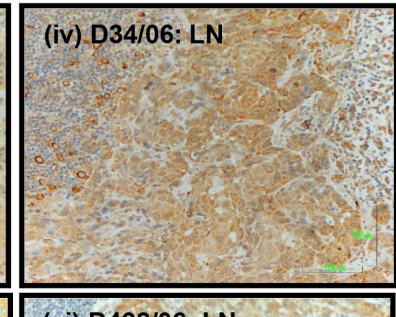

(vi) D498/06: LN

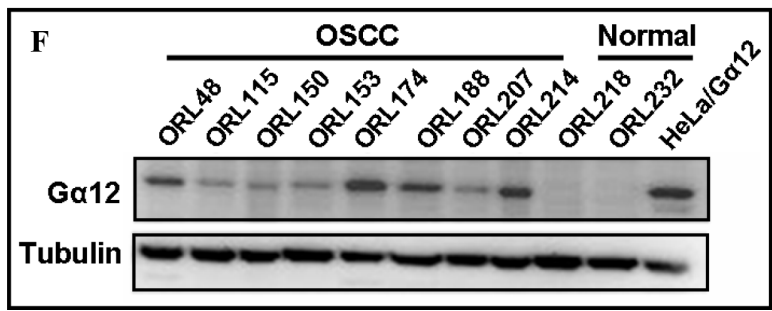

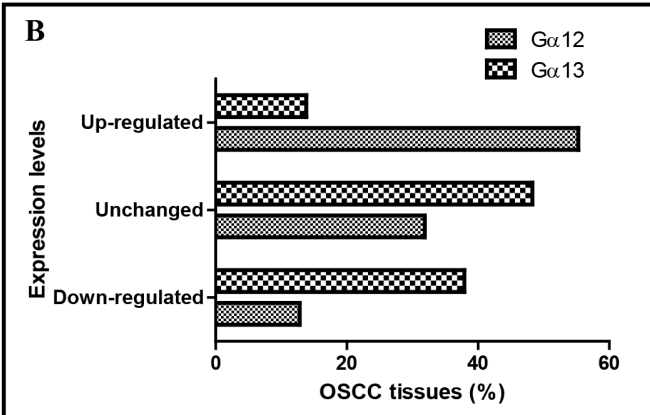

tissues (\%)
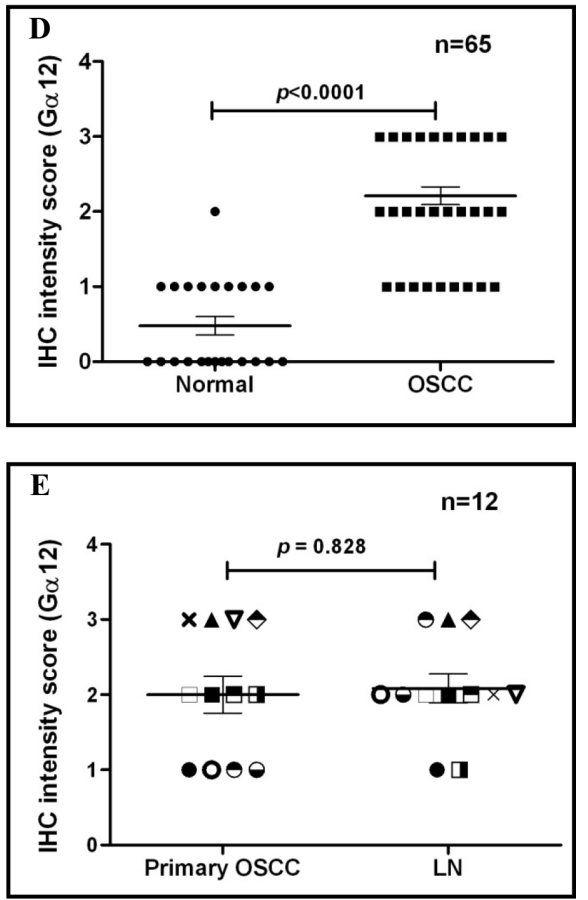

Figure 1: Overexpression of Ga12 in oral squamous cell carcinoma (OSCC) tissues and cell lines. (A) qPCR analysis indicated that $\mathrm{G} \alpha 12$ was significantly overexpressed at the mRNA level in OSCC tissues. As indicated by the box and whiskers plot, OSCC tissues had a median of 2.35-fold increase in Ga12 expression, with a maximum level of 23-fold overexpression compared to normal oral mucosa (NOM). Meanwhile, the median of Ga13 expression is 1.1-fold, suggesting no differential expression between OSCC and NOM. (B) Ga12 mRNA levels were found to be overexpressed in 55.3\% of OSCC tissues examined, and majority of the OSCC tissues had downregulation of $\mathrm{G} \alpha 13$, when using a cut-off fold-change value of $\geq 2$. (C) IHC images showing NOM tissues have negative staining for Ga12 (panel i \& ii), but the primary tumors and the LN of matched cases showed overexpression of Ga12 (panel iii \& iv; panel v \& vi). Images were captured using 200x objective. (D) IHC staining analysis indicated that $\mathrm{G} \alpha 12$ is overexpressed in the primary tumors compared to NOM tissues. (E) Expression of Ga12 was also retained in the OSCC cells that metastasized to the lymph nodes (LN). Each symbol represents one patient. Error bars in IHC analyses represent standard error of the means (SEM) of Ga12 expression for the total number of tissues examined. (F) Western blot indicated Ga12 is overexpressed in all OSCC cell lines and absent in normal oral keratinocyte primary cultures. $\alpha$-tubulin was used as an endogenous control and squamous non-oral HeLa cells transformed to overexpress Ga12 was used as a positive control. 
Table 1: Association of Ga12 protein expression with clinicopathological data

\begin{tabular}{|c|c|c|c|c|}
\hline \multirow[b]{2}{*}{ Characteristics } & \multicolumn{4}{|c|}{ Ga12 expression } \\
\hline & $\begin{array}{c}\text { Patient } \\
\text { n }\end{array}$ & $\begin{array}{c}\text { Low } \\
\text { n (\%) }\end{array}$ & $\begin{array}{l}\text { High } \\
\text { n (\%) }\end{array}$ & p-value \\
\hline \multicolumn{5}{|l|}{ Broder's grading } \\
\hline Well & 16 & $3(18.8)$ & $13(81.2)$ & $0.709^{+}$ \\
\hline Moderate & 20 & $5(25.0)$ & $15(75.0)$ & \\
\hline \multicolumn{5}{|l|}{ Tumor size } \\
\hline $\mathrm{T} 1 \& \mathrm{~T} 2$ & 16 & $6(37.5)$ & $10(62.5)$ & $0.123^{+}$ \\
\hline $\mathrm{T} 3 \& \mathrm{~T} 4$ & 23 & $3(13.0)$ & $20(87.0)$ & \\
\hline \multicolumn{5}{|l|}{ Lymph nodes } \\
\hline Negative & 21 & $4(19.0)$ & $17(81.0)$ & $0.706^{+}$ \\
\hline Positive & 18 & $5(27.8)$ & $13(72.2)$ & \\
\hline \multicolumn{5}{|l|}{ Stage } \\
\hline $\mathrm{I} / \mathrm{II}$ & 8 & $2(25.0)$ & $6(75.0)$ & $1.000^{+}$ \\
\hline III/IV & 31 & $7(22.6)$ & $24(77.4)$ & \\
\hline \multicolumn{5}{|c|}{ Pattern of invasion } \\
\hline Cohesive & 10 & $1(10.0)$ & $9(90.0)$ & $0.410^{+}$ \\
\hline Non-cohesive & 31 & $8(25.8)$ & $23(74.2)$ & \\
\hline
\end{tabular}

Ga12 and Ga13 in ORL48 cells (Figure 3A), but was demonstrated to behave as a dominant negative mutant for G12 signaling by inhibiting LPA and thrombin dependent RhoA activation (Figure 3B). We observed that the endogenous level of activated RhoA was slightly higher in the ORL48/RGS control (0 time point). The levels of activated RhoA in ORL48/GFP control were markedly induced upon LPA and thrombin stimulations, respectively as early as 30 seconds. Interestingly, the levels of activated RhoA in ORL48/RGS remained low for up to 10 minutes of LPA and thrombin stimulations, indicating that the expression of the GFP-fused RGS chimeric molecule inhibited LPA- and thrombin-mediated G12-RhoA signaling axis.

As the presence of RGS inhibited the G12-mediated RhoA activation biochemically, we next examined if the presence of RGS in ORL48 was likely to confer a functional outcome. Here, we showed that the inhibition of G12 signaling by the GFP-fused RGS chimeric molecule caused a significant reduction of migration capacity as indicated by the open wound area in ORL48/RGS, which was $85.6 \%$ compared to $45.6 \%$ in the ORL $48 /$ GFP cells $(p<0.001$, Figure $3 C)$. To confirm that this reduction in migration was due to reduced Go12 functional activity through RGS, we decided to use a knockdown approach of reducing endogenously high levels of this protein in ORL48 cells. As seen in Figure 3D, the two shRNA sequences for $\mathrm{G} \alpha 12$ were able to reduce $\mathrm{G} \alpha 12$ protein levels to $44 \%$ (shGa12 322311) and $22 \%$ (shGal2 322313 ), and when these cell populations with controls were tested for their potential in cell migration and invasion, we noted that there was a significant reduction in cell motility and invasiveness in ORL48/shGa12 cells, compared to mocked transfected cells (Figure 3E). Knockdown of Ga12 in ORL48 led to $\sim 30 \%$ and $70 \%$ reduction in cell migration and invasion in response to the NIH3T3 cells conditioned medium and thrombin, respectively. Altogether, these findings strongly suggest that both activation as well as overexpression of $\mathrm{G} \alpha 12$ can lead to OSCC cell migration and invasion.

\section{Inhibition of Ga12 signaling reduced OSCC metastasis to $\mathrm{LN}$ in the orthotopic xenograft model}

OSCC frequently metastasize to the lymphatic basin in the neck area. Given that the oral tongue is composed of a dense lymphatic network, we developed an orthotopic model of OSCC metastasis by injecting ORL48 cells into the posterior of the tongue of NOD/ SCID mice. Following the same model as previously reported [22], ORL48 cells formed moderately differentiated tumors within 20 days and were noted to be highly aggressive, invading the muscle and 

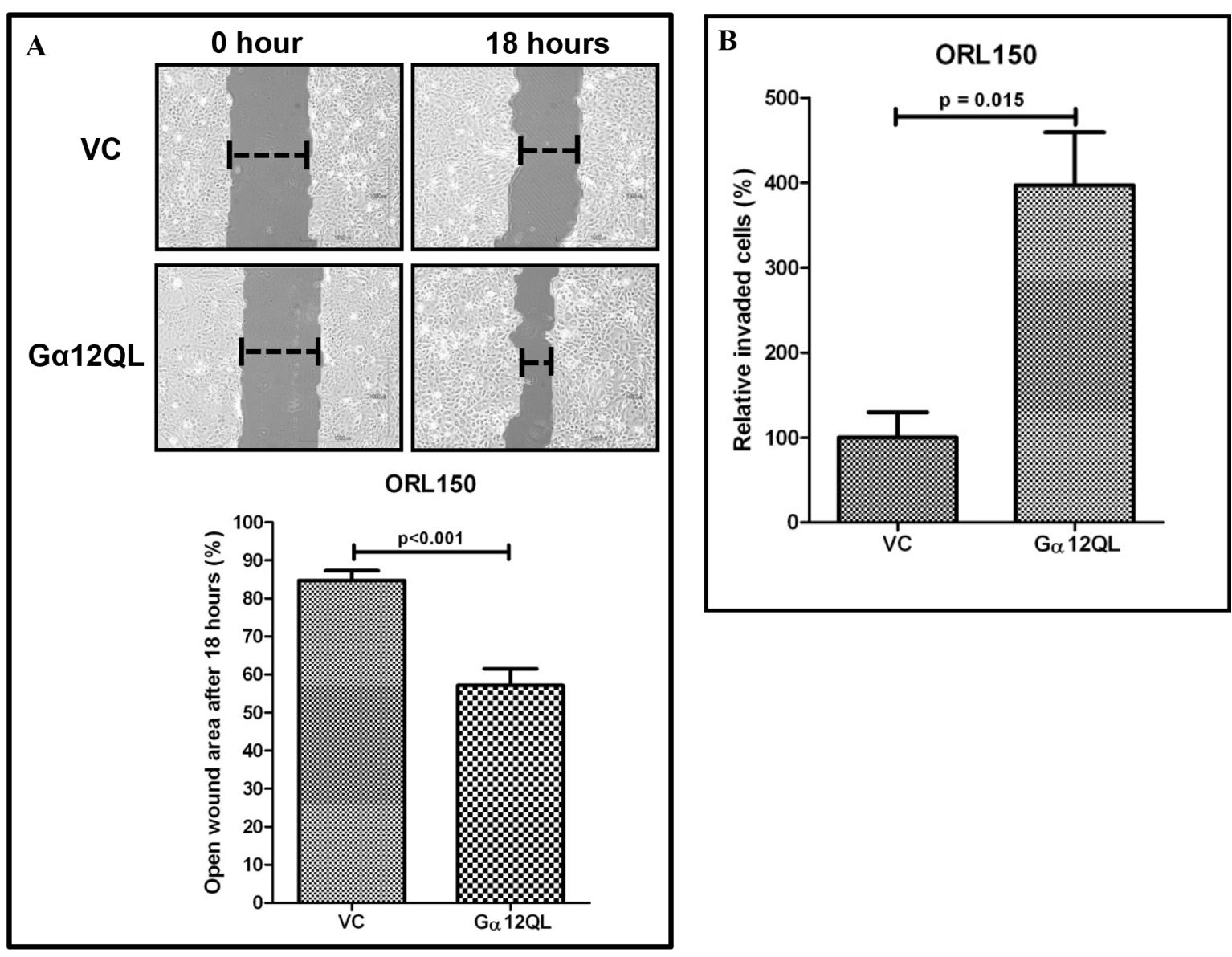

Figure 2: Activation of Ga12 promotes OSCC cell migration and invasion. (A) The functional effect of the constitutive

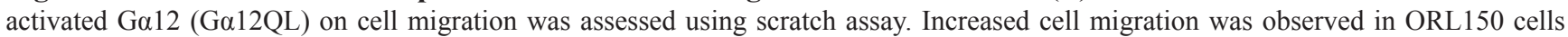
that overexpress G $\alpha 12 \mathrm{QL}$ as indicated by a significant reduction in the open wound area, as compared to the ORL150/VC cells after 18 hours. (B) Similarly, ORL150/Ga12QL cells demonstrated 4-fold increase in invasion in comparison to the ORL150/VC cells. NIH3T3 conditioned medium was used as chemoattractant. The graphs are the representative results of 3 experimental repeats. Error bars represent SEM for the replicates tested in an experiment.

surrounding tissues (Supplementary Figure 3A). More importantly, ORL48 cells also metastasized into the cervical LNs (Supplementary 3B). With this information of the physiopathological behavior of ORL48 cells in vivo, and that the overexpression of RGS inhibits G12 signaling in ORL48 cells in vitro, we next assessed the impact of ORL48/RGS cells on OSCC spread to LN in the orthotopic-tongue mouse model. Both ORL48/GFP and ORL48/RGS cells formed ulcerating and highly aggressive tumors on the tongue of NOD/SCID mice after 20 days. Histopathological evaluation of the primary tumors indicated that the tumor had invaded into the muscle and the surrounding tissues (Figure 4A, i and iii). Perhaps of importance, no difference in the primary tumor volume was observed between the two groups (Figure 4B). Furthermore, we observed that 12 out of the $14(85.7 \%)$ animals injected with ORL48/GFP control cells had OSCC spread to their cervical LN, while only 7 out of $15(46.7 \%)$ animals injected with ORL48/RGS cells showed metastatic spread (Figure 4A, ii and iv). This difference in prevalence of LN metastasis (Figure $4 \mathrm{C}$; $p=0.027$ ), suggests that inhibition of G12-RhoA signaling axis is not involved in regulating tumor growth but is pivotal for the inhibition of OSCC metastatic progression. In addition, we noticed that mice orthotopically injected with ORL48/GFP cells had higher mortality rate, as 5 out of 19 mice died before day 20 whilst no deaths were noted in the corresponding ORL48/RGS cohort during this experimental period (data not shown). Taken together, our results indicated that targeting the G12 signaling pathway may be an effective approach to prevent metastasis burden in OSCC patients.

\section{Ga12 is not involved in OSCC cell proliferation}

To examine the effect of Ga12 on OSCC cell growth, we compared ORL150 cells expressing Ga12QL with VC cells. Activation of Ga12 had no effect on OSCC 

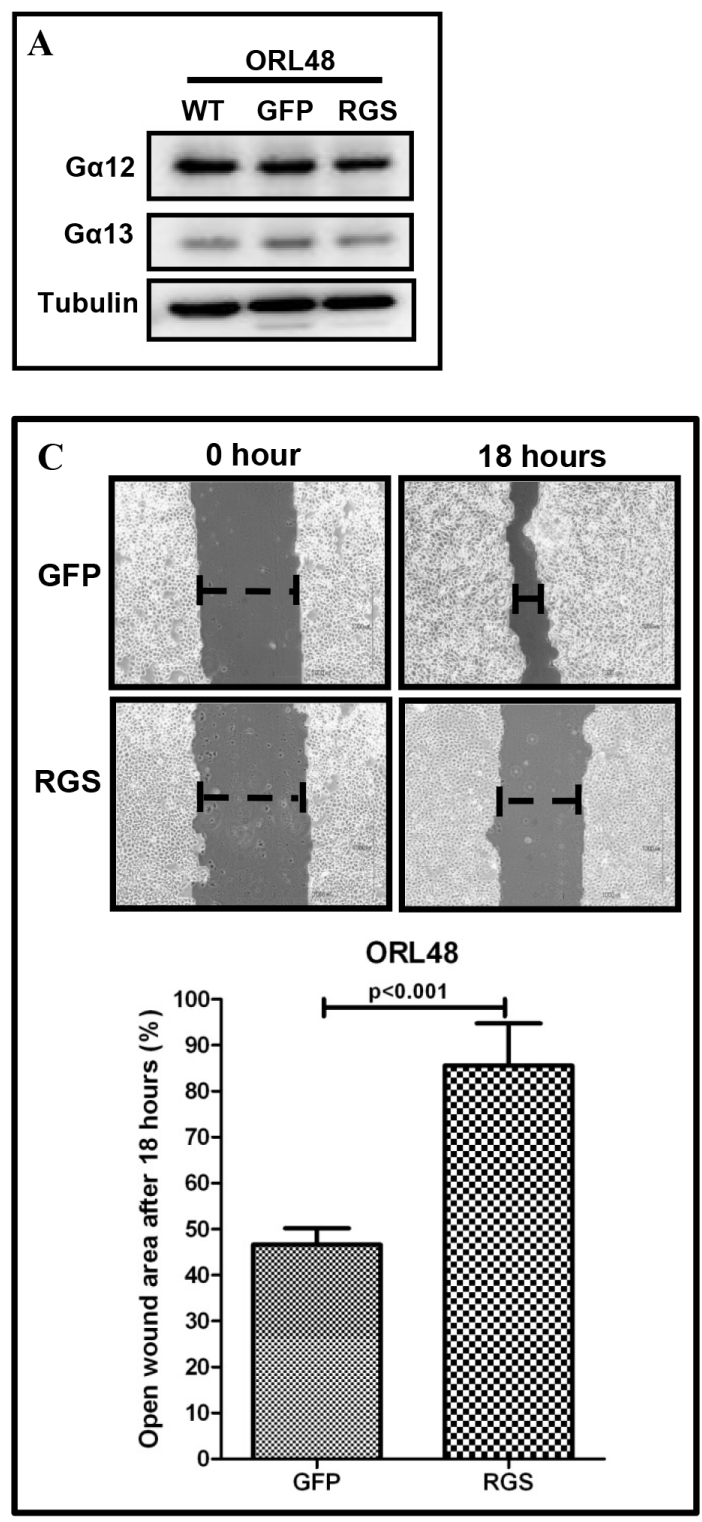
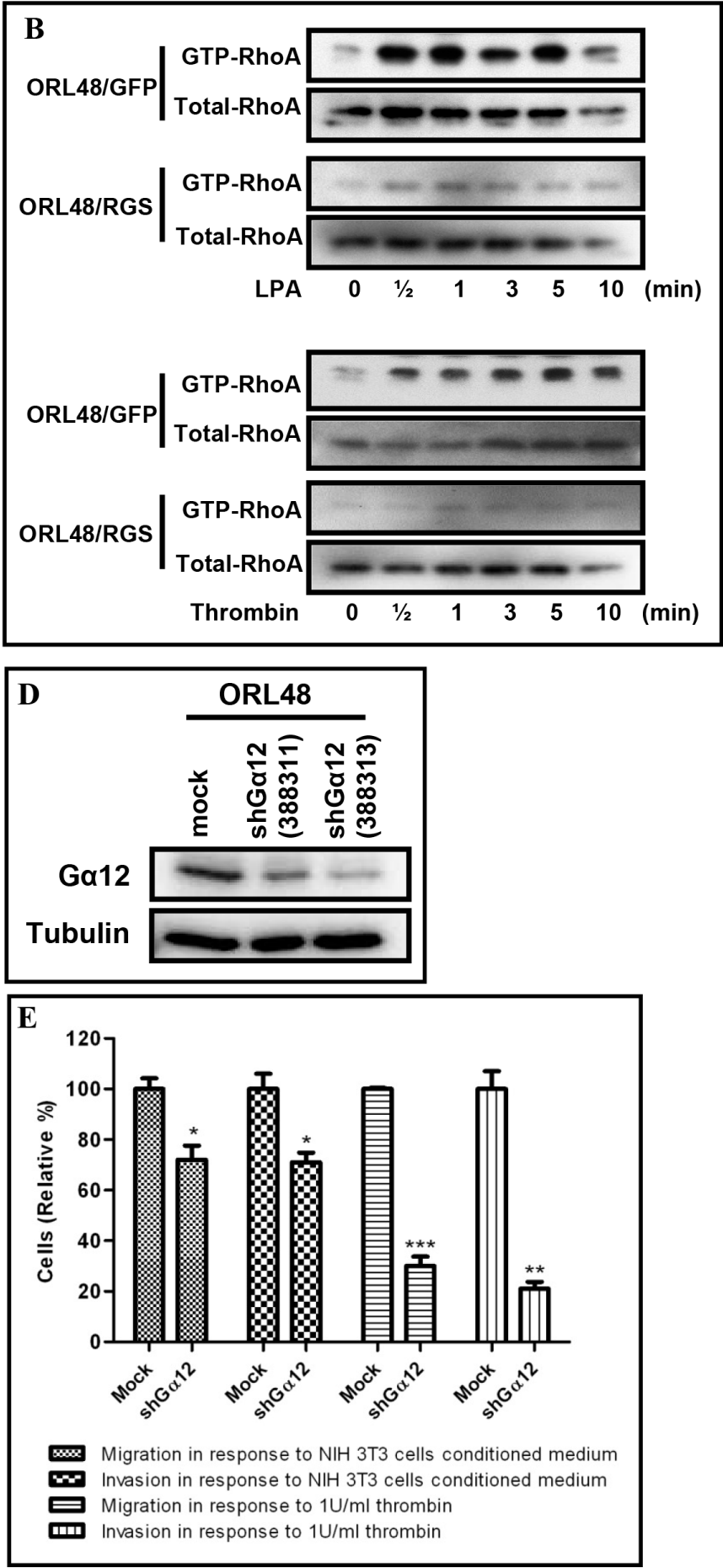

Figure 3: Inhibition of G12 signaling and knockdown of Ga12 in OSCC. (A) Total protein levels of Ga12 and Ga13 were not affected in ORL48 cells transduced with GFP-fused RGS chimeric molecule. (B) Endogenous levels of activated RhoA were reduced in ORL48/RGS cells and remained inhibited even up to 10 minutes post LPA and thrombin stimulation, as compared to the ORL48/ GFP control. (C) In scratch assays, the expression of GFP-fused RGS chimeric molecule in ORL48 consistently inhibited cell migration, as indicated by a significant larger open wound area compared to the ORL48/GFP control cells after 18 hours. (D) The expression of

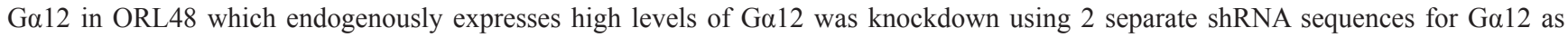
shown by western blot. (E) Ga12 knockdown in ORL48 by shRNA inhibited OSCC cell migration and invasion in the transwell assays. ORL48/shG $\alpha 12$ cells showed a significant reduction in cell migration and invasion when tested with 2 different chemoattractant (NIH3T3 conditioned medium and $1 \mathrm{U} / \mathrm{ml}$ thrombin). The graphs are the representative results of 3 experimental repeats. Error bars represent SEM for the replicates tested in an experiment. 

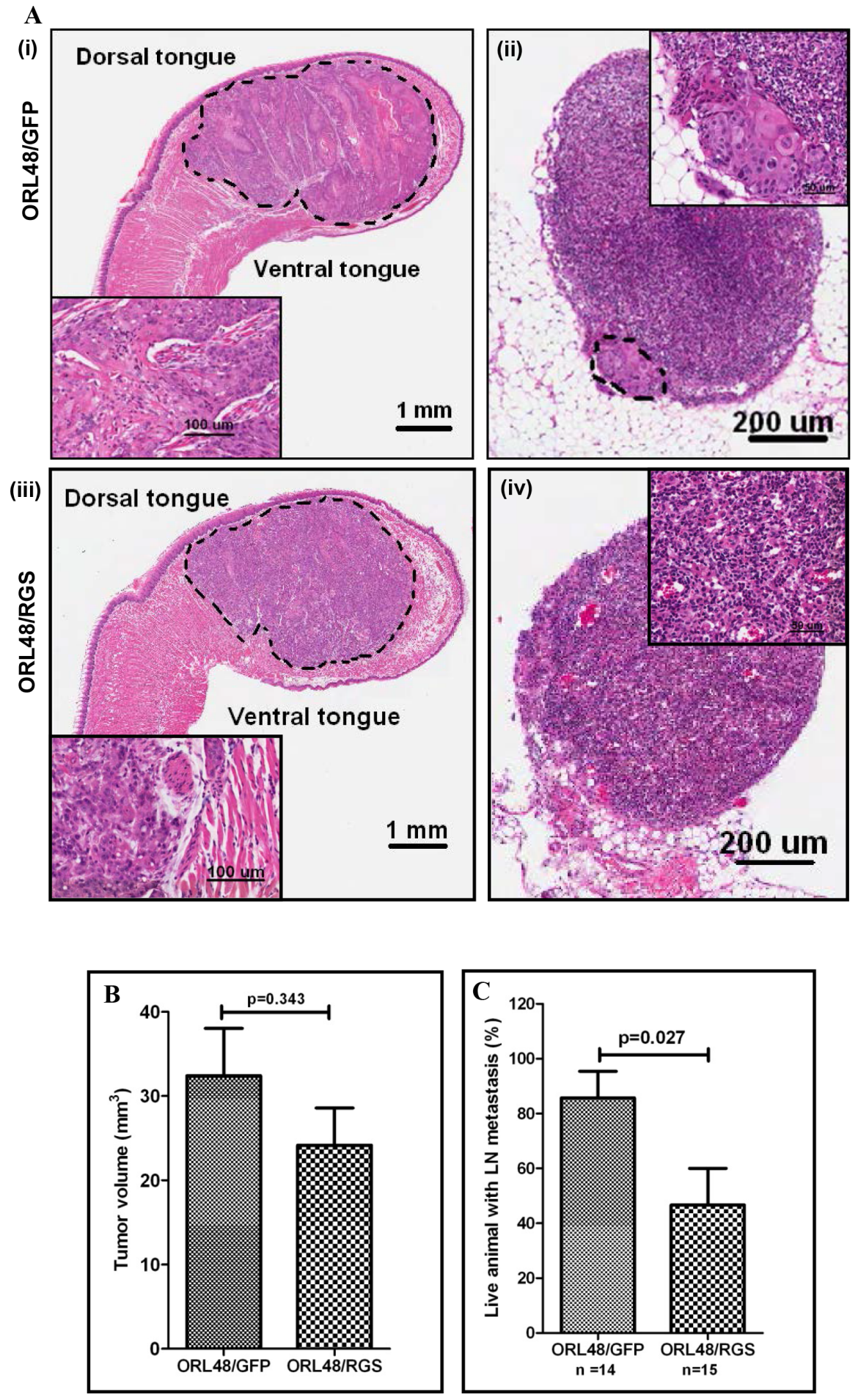

Figure 4: G12-RhoA signaling axis is involved in OSCC metastasis to cervical lymph nodes (LN). (A) H\&E-stained tissue section of the orthotopically implanted OSCC cells into the tongue. ORL48/GFP control cells (i) and ORL48/RGS (iii) formed primary tumors growing into the anterior half of the tongue after day 20 post-implantation. Insets are higher magnification of the tumor area. Histologic evaluation of H\&E-stained sections of the representative cervical lymph node showing the metastatic growth of ORL48/GFP control cells in the area rounded by dotted line. Inset is the higher magnification of the metastatic area (ii). Histological section of a noninvaded lymph node in the ORL48/RGS group (iv). (B) The growth of ORL48/GFP (control) primary tumors on the tongue were larger than those of the ORL48/RGS tumors, but the differences were not statistically significant. (C) Increased number of metastatic LN was found in mice carrying orthotopic ORL48/GFP control tumors, as compared to ORL48/RGS tumors. Animals that died of the disease before day 20 post-implantation were not included in the analysis as their LN were difficult to retrieve. The bar chart represents the average percentage of total animals that showed LN metastasis in 3 sets of experiments, while the error bars are SEM for these experiments. 


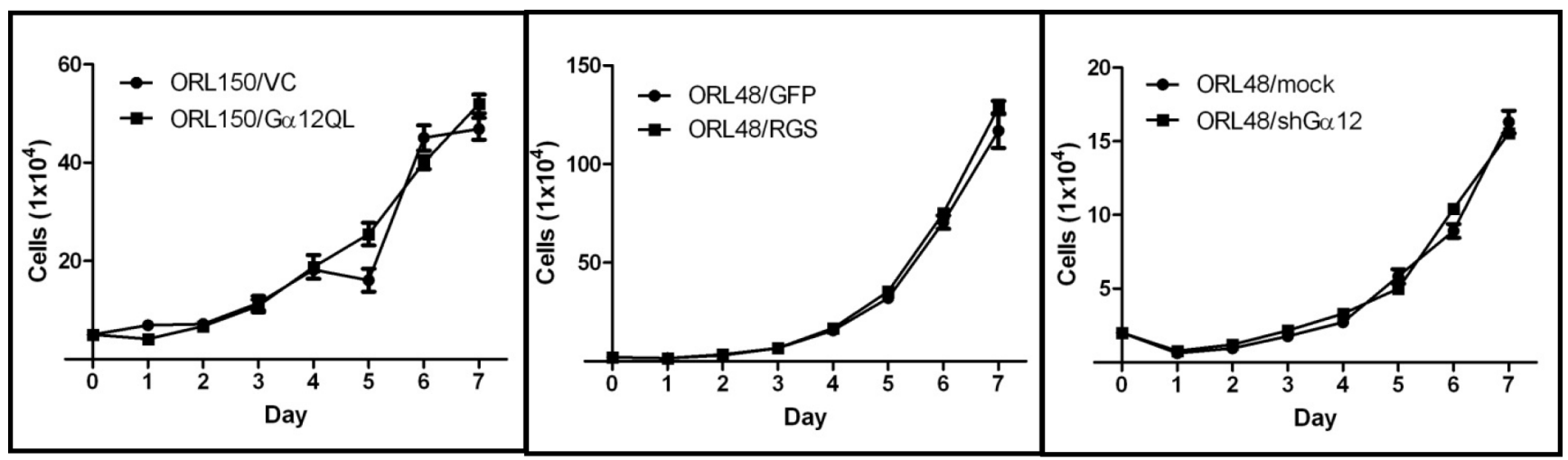

Figure 5: Ga12 is not involved in regulating OSCC proliferation. No differences in cell growth were observed whether Ga12

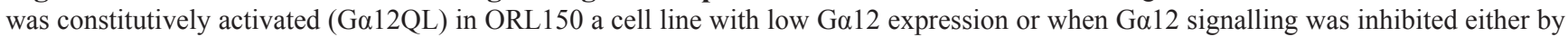

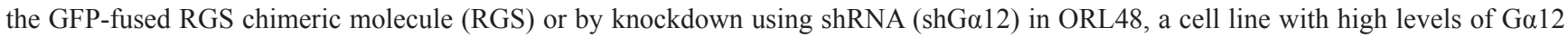
expression. The graphs are the representative results of 3 experimental repeats. Error bars represent SEM for the replicates tested in an experiment.

cell growth (Figure 5). This observation was confirmed in ORL48/RGS and ORL48/shGa12 cells, where no significant differences in the proliferation rate were found when compared to their respective control cells. These findings were consistent with our observation in the animal studies, whereby inhibition of G $\alpha 12$ signaling has no effect on tumor volume (Figure 4B), suggesting that $\mathrm{G} \alpha 12$ is not involved in driving OSCC cell proliferation.

\section{DISCUSSION}

When the spread of OSCC involves LN metastasis, the prognosis of the patient is significantly reduced and treatment becomes limited and invariably aggressive. Unfortunately, approximately half of OSCC patients present with metastatic cervical nodes at the time of diagnosis or follow-up [23], hence understanding the molecular mechanisms underlying OSCC progression from a localized growth to LN metastasis is critical to effectively prevent disease recurrence and ultimately improve survival. In this study, we further validated our previous observations that $\mathrm{G} \alpha 12$ is overexpressed in an independent OSCC sample cohort, suggesting an oncogenic role for $\mathrm{G \alpha} 12$ that warranted further investigation. Data from our current findings are in-line with studies reported in other solid cancers including nasopharyngeal cancer [18], adenocarcinomas of the breast and prostate $[16,17]$, as well as cell lines derived from different tumor origins [24]. The basis of the elevated $\mathrm{G} \alpha 12$ levels observed in our samples is unclear, but emerging data from our group have noted that all our OSCC cell lines with the exception of ORL214 showed chromosomal amplification at the region where Ga12 resides (7p22.2) (unpublished copy number alterations data). More importantly, studies have shown that Ga12 in the overexpressed and constitutively activated form harbors transforming capability [14, 15]. Studies on other $\mathrm{G} \alpha$ subunit family members showed that constitutively active mutants of $\mathrm{G} \alpha \mathrm{q}$ and $\mathrm{G} \alpha 11$ are considered as driver oncogenes in $66 \%$ of ocular melanomas [25]. However, unlike the activating mutations found in other $\mathrm{G} \alpha$ subunit family, whereby these hotspot mutations reduced the rate of GTP hydrolysis of the active GTP-bound G $\alpha$ subunit, resulting in constitutive signaling activity, human tumors carrying mutations that activate $\mathrm{G} \alpha 12$ have yet to be reported to date [25-27]. In fact, in head and neck cancers, $\mathrm{G} \alpha 12$ mutation frequency has been largely found to be low (1.3\%). It is possible that mutations in GPCRs coupled to G12 family that are frequently found in other cancers provide an oncogenic advantage, hence additional gain-of-function mutations in these G-proteins may not be frequently observed [25]. Following our observation that high levels of Ga12 are predominantly detected in OSCC and not in NOM tissues, it is possible that Ga12 may acquire an oncogenic transforming ability in the overexpressed form, compared to other heterotrimeric $\mathrm{G} \alpha$ proteins which have to attain the constitutively GTPbound form to induce transformation.

It is noteworthy that Ga12 and its G12 subfamily counterpart, G $\alpha 13$, share $67 \%$ amino acid identity [6], and both appear to interact with the same receptors and downstream effectors in mediating cell signaling [28, 29]. In this study we determined that while Ga13 levels remained unchanged, Ga12 levels were observed to be largely overexpressed in our OSCC tissue cohort, indicating the importance of $\mathrm{G} \alpha 12$ in OSCC tumorgenesis and progression. In this context, studies have suggested that the functions of $\mathrm{G} \alpha 12$ and $\mathrm{G} \alpha 13$ may not completely overlap, whereby $\mathrm{G} \alpha 12$ has been demonstrated to be more potent in inducing oncogenic transformation including cell shape changes and migration [15, 30], while Ga13 was noted to be more active in inducing angiogenesis and apoptosis [12, 31]. 
Several studies have demonstrated that overexpression of $\mathrm{G \alpha} 12$ is associated with tumor invasiveness [16-18, 32]. In this regard, our IHC analysis of Ga12 on OSCC samples showed no association between Ga12 expression in the primary tumors and LN metastasis, but intriguingly high levels of this protein were found to be retained in the OSCC cells that had metastasized into the LN. More recently, during the preparation of this manuscript, Jian and colleagues [32] also found no association between $\mathrm{G} \alpha 12$ overexpression and LN status in OSCC patients, but showed that Ga12 overexpression significantly correlated with extracapsular spread.

We further examined the function of $\mathrm{G} \alpha 12$ in OSCC. Although both activation by the use of Ga12 GTPase

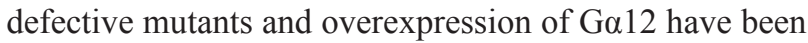
demonstrated to have transformation properties [14-16], we focused here on the use of an activated G $\alpha 12$ mutant as it may facilitate the analysis of its consequences and to minimize the variability that may be caused by relying on overexpression and likely activation by endogenously expressed Ga12-coupled receptors. Our in vitro data demonstrated that expression of constitutively activatedGa12 increased OSCC cell migration and invasion. We also demonstrated that inhibition of $\mathrm{G} \alpha 12$ expression in OSCC cells by shRNA markedly inhibited OSCC cell migration and invasion. Perhaps it is not too surprising to find that deregulation of G12 promotes cell migration and invasion in cancer development, since physiologically, normal G12 proteins regulate cell polarity, cytoskeletal rearrangement and processes governing cell shape changes which are essential in controlling cell motility during embryonic development [8, 9]. In addition, they also regulate the migration of lymphocytes, neutrophils and vascular smooth muscle cells [33-36].

Signaling by G12 proteins are responsible for the Rho-dependent cytoskeletal changes required for cell migration [28, 34, 37, 38]. Activation of G12 signaling by PAR-1 and LPAR inducing cancer cell invasion have been shown to be mediated by Rho proteins in breast and prostate cancers $[16,17,39]$. Here, we investigated the G12-RhoA signaling axis in OSCC, whereby expression of RGS blocked G12 downstream signaling as indicated by the reduction in LPA- and thrombin-dependent RhoA activation. Blockade of G12 signaling by RGS resulted in the inhibition of OSCC cell migration in vitro. In support, RGS expression has been reported to block G12 signaling in triple-negative breast cancer cell lines, reduced SDF-1dependent Rho activation, causing a reduction in invasion and migration [19]. Although we did not further examine the downstream G12 signaling mechanism in mediating cytoskeletal changes, it is possible that RhoA promotes changes in the cytoskeletal architecture through ROCK, and the remodeling of focal adhesion components through protein kinase C-related kinase to collectively cause cellcell junction disruption [38]. Interestingly, G12 subfamily can couple to the CXCR4 chemokine receptor and drive tumor spread to specific organs in RhoA dependent manner [19]. Also, G12 can enhance cell motility and invasion independently of Rho proteins, such as by reducing cellextracellular matrix adhesion through integrins [40], decreasing the rigidity of cell-cell contacts by reducing the stability of homophilic E-cadherin interactions [41], as well as by activating transcription factors that control the expression of metalloproteases such as matrix-metalloproteinase (MMP)-2 and MMP-9 [29]. In a recent study, Ga12 signaling was shown to mediate OSCC invasion by up-regulating proinflammatory cytokines [32], suggesting that Go12 is a critical player in the inflammatory cytokines pathways during OSCC tumorigenesis. In support of these observation, we have recently reported that these proinflammatory cytokines (IL-6 and IL-8) were found to be elevated in the serum samples of OSCC patients using a novel antibody based screening device [42], suggesting that high Ga12 level may be causal for the induction of these cytokines.

More importantly, we further demonstrated that RGS mediated inhibition of G12 signaling significantly reduced the metastatic dissemination of OSCC cells from the primary tumor mass to the LNs irrespective of size, suggesting that G12 signaling does not impact the growth of the primary tumor but is likely to drive metastasis. In support of these observations, previous studies on breast cancer also showed that the blockade of G12 downstream signaling resulted in a notable impact on the metastatic spread that resulted in a significant increase in metastasisfree survival of mice [16]. As mentioned earlier, OSCC has a high potential to spread to the cervical LNs, therefore any strategies that may result in locoregional control of the disease will play an important role in improving patient survival. Thus, these findings suggest that interfering with the G12-Rho signaling axis and their key down-stream targets may provide previously unexplored options to halt OSCC metastasis.

Several studies have indicated that Ga12 may be an important promoter for cell growth in certain cell types, as this molecule in its wild-type and activated-form has been shown to be involved in the proliferation of fibroblasts [14, 15, 30, 43, 44]. In this study, both Ga12 expression and activation consistently showed no effect in OSCC cell proliferation in in vitro results, suggesting that $\mathrm{G} \alpha 12$ is not crucial in regulating OSCC cell growth and proliferation. In support of our in vitro findings, our in vivo data also suggested that the growth of primary tumors on the tongue were not affected, despite the reduction in LN metastasis when G12 signaling was inhibited by RGS. Our findings are in agreement with those reported by Kelly and colleagues $[16,17]$. 
These differences seen in the role of G12 in controlling cell proliferation may be due to the intrinsic properties of the tumor and also the different cellular origin such as the mesenchymal (fibroblasts) versus epithelial cells, as Ga12 may exert specific effects through the different down-stream signaling pathways [37].

In conclusion, the overexpression of Ga12 in OSCC may be required for the amplification of G12 signaling to promote the transforming effects of this oncogene. Further, our data collectively support the functional significance of Ga12 in OSCC tumor metastasis that has also been reported in other human cancers $[16,17]$. The presence of LN metastasis in OSCC represents the most important factor predicting a poor prognosis [45], and unfortunately there are still limited therapeutic options to prevent disease progression and OSCC spread. Many studies including ours have indicated that perturbing the G12 signaling may provide a reasonable approach to preventing metastasis in patients at risk.

\section{MATERIALS AND METHODS}

\section{Tissue specimens}

All clinical human tissues used in this study were collected with informed consent, and was approved by the ethical review board at the Faculty of Dentistry, University of Malaya (Ethical approval code: DFOP0703/0017). Frozen tissues comprising of 47 OSCC and 18 normal oral mucosa (NOM) tissues were used in this study. NOM specimens were obtained from the gingiva of individuals who did not have OSCC but had undergone wisdom tooth removal. In addition, the formalin-fixed paraffin-embedded (FFPE) tissue specimens used in this study include 42 OSCC specimens, 10 fibro-epithelial polyps (FEP), 13 NOM and 12 metastatic cervical LN specimens that are matched to primary tumors. The diagnoses of all tissue specimens used in this study were histopathologically confirmed by an oral pathologist (RBZ). The socio-demographic information of the patient cohort was obtained from the Malaysian Oral Cancer Database and Tissue Bank System (MOCDTBS) [46], and this is summarized in Table 2.

\section{RNA extraction and cDNA synthesis}

Total RNA was extracted from frozen tissues containing at least 70\% tumor cells (OSCC specimens) or normal epithelial cells (for NOM) using the RNeasy Micro kit (Qiagen, Germany), according to the manufacturer's instructions. The quality and quantity of RNA extracted from these samples were evaluated using the Agilent 2100 Bioanalyzer (Agilent Technologies, USA). cDNA was synthesized from $2 \mu \mathrm{g}$ of total RNA using the High

\section{Table 2: Demographic distribution of 42 OSCC cases used in Ga12 IHC analysis}

\begin{tabular}{|c|c|c|c|}
\hline & \multirow{2}{*}{ Variables } & \multicolumn{2}{|c|}{ OSCC } \\
\hline & & $\mathbf{n}$ & $(\%)$ \\
\hline Age (year) & Mean \pm SD: $61 \pm 10$ & & \\
\hline \multirow[t]{2}{*}{ Gender } & Male & 12 & (28.6) \\
\hline & Female & 30 & (71.4) \\
\hline \multirow[t]{4}{*}{ Ethnic } & Malay & 6 & $(14.3)$ \\
\hline & Chinese & 3 & (7.1) \\
\hline & Indian & 32 & $(76.2)$ \\
\hline & Others & 1 & (2.4) \\
\hline \multirow[t]{4}{*}{ Primary site } & Cheek & 25 & $(59.5)$ \\
\hline & Gum & 11 & $(26.2)$ \\
\hline & Tongue & 5 & (11.9) \\
\hline & Others & 1 & (2.4) \\
\hline \multirow[t]{5}{*}{ Habit } & No habit & 4 & (9.5) \\
\hline & Chew betel quid & 22 & $(52.4)$ \\
\hline & Smoking & 4 & (9.5) \\
\hline & Drink alcohol & 1 & (2.4) \\
\hline & More than 1 risk habit & 12 & (28.6) \\
\hline
\end{tabular}


Capacity cDNA Reverse Transcription kit (Applied Biosystems, CA, USA) in a total volume of $100 \mu \mathrm{l}$, as described previously [20].

\section{Quantitative PCR (qPCR)}

qPCR was performed with standard SYBR Green protocol using the ABI PRISM ${ }^{\circledR} 7000$ Sequence Detection System (Applied Biosystems, Germany), as described previously [20]. Briefly, reactions were carried out by performing a pre-incubation for 10 minutes at $95^{\circ} \mathrm{C}$, followed by 40 amplification cycles at $95^{\circ} \mathrm{C}$ for 15 seconds and $60^{\circ} \mathrm{C}$ for 1 minute. The primers used were as follow:

$\mathrm{G} \alpha 12$

sense

$5 \square$ ATAAGTCAGATTGTTAACTCCAAGATTGA3 $\square$

Ga12antisense $\square$ AGCCAGACCCTCCCAATGTT3 $\square$

Ga13 sense $5 \square$ GGGCAGGACTTCGACCAGCG3 $\square$

Ga13antisense5 $\square$ CCATGGGGGCCCGGGTATCA3 $\square$

GAPDHsense $5 \square$ GAAGGTGAAGGTCGGAGTC3 $\square$

GAPDH

antisense

\section{$5 \square$ GAAGATGGTGATGGGATTTC3 $\square$}

Relative quantification was performed by comparative $\mathrm{Ct}$ method to normalize the expression of Ga12 and Ga13 to the housekeeping gene GAPDH. Relative expression of target genes in OSCC were determined against $\mathrm{Ct}$ values of the NOM tissues.

\section{Immunohistochemistry (IHC)}

The expression of $\mathrm{G} \alpha 12$ was examined by IHC using the Dakocytomation Envision+ Dual Link SystemHRP (DAB+) kit (Dako, Glostrup, Denmark). IHC was performed on the FFPE primary OSCC tissues and 12 available matching lymph node tissues as described previously [47]. The Ga12 polyclonal antibody (SC-409; Santa Cruz Biotechnology, CA, USA) was used as the primary antibody at a dilution of 1:75. Immunoreactivity of epithelial cells (cancer and normal) was scored based on a 4-point intensity scoring system: $0=$ negative expression; 1 = weak positive; 2 = moderate positive; $3=$ strong positive as described previously $[16,17]$. All IHC analysis was evaluated independently by a pathologist (RBZ). The receiver operating characteristic (ROC) curve was used to identify the best cut-off points in scoring the expression of $\mathrm{G} \alpha 12$ for specificity and sensitivity, whereby scores of 1 or 2 would be grouped as low expression, while 3 or 4 would be considered as high expression.

\section{Cell culture}

Asian OSCC cell lines (ORL48, ORL115, ORL150, ORL153, ORL174, ORL188, ORL207, ORL214) used in this study were previously established in our laboratory as described [47]. Prior to use, all lines underwent authentication using the $\mathrm{AmpF} / \mathrm{STR}^{\circledR}$ Identifier $^{\circledR}$ PCR
Amplification kit (Applied Biosystems, USA). All OSCC cell lines were cultured in Dulbecco's Modified Eagle's Medium/Nutrient mixture F-12 HAM's medium (DMEM/F-12; Hyclone, Utah, USA) supplemented with $500 \mathrm{ng} / \mathrm{ml}$ hydrocortisone (Sigma-Aldrich, MO, USA), and $10 \%$ fetal bovine serum (FBS; Gibco, Auckland, NZ). Normal oral keratinocytes primary cultures (ORL218 and ORL232) established in our laboratory from healthy gingival biopsies, were maintained in Keratinocyte Serum-Free Medium (KSFM; Gibco, Auckland, NZ) supplemented with $25 \mu \mathrm{g} / \mathrm{ml}$ bovine pituitary extract, $0.4 \mathrm{ng} / \mathrm{ml}$ epidermal growth factor, and $0.09 \mathrm{mM} \mathrm{CaCl}_{2}$. Mouse NIH3T3 and packaging cell lines HEK-293T, GP-293 (Clontech, CA, USA), were grown and maintained in DMEM high glucose medium (Gibco, Auckland, NZ) containing $10 \%$ FBS.

\section{Overexpression of activated Ga12 in OSCC}

The Ga12QL plasmid was a kind gift from Dr. Patrick Casey (Duke University Medical Centre). GP-293 packaging cells were grown in a $60 \mathrm{~mm}$ dish until $70 \%$ confluence ( $\sim 24$ hours) prior to transfection. Retroviral stock was prepared by co-transfecting $5 \mu \mathrm{g}$ of pLXRN (vector control [VC]) or Ga12QL with $5 \mu \mathrm{g}$ of pVSVG (envelope) into the GP-293 packaging cells using Lipofectamine 2000 (Invitrogen, CA, USA), according to the manufacturer's instructions. The supernatants containing the retrovirus were harvested after 48 hours and filtered through $0.45 \mu \mathrm{m}$ PVDF syringe filter. ORL150 cells expressing low levels of $\mathrm{G} \alpha 12$ were seeded at $1 \times 10^{5}$ cells in a $60 \mathrm{~mm}$ dish 18 hours prior to retroviral infection. Then, filtered viral supernatant was added onto the ORL150 cells with $10 \mu \mathrm{g} / \mathrm{ml}$ polybrene (Sigma-Aldrich, MO, USA). Successfully transduced cells were selected with $75 \mu \mathrm{g} / \mathrm{ml} \mathrm{G418} \mathrm{(Sigma-Aldrich,} \mathrm{MO,} \mathrm{USA).}$

\section{Inhibition of G12 signaling by RGS}

The green fluorescence protein (GFP)-fused to the regulator of G-protein signaling (RGS) domain of PDZ-RhoGEF has been previously described by Basile and colleagues [48]. HEK-293T packaging cells were grown in a 6-well plate until $70 \%$ confluence ( $\sim 24$ hours) prior to transfection. Lentiviral stock was prepared by co-transfecting RGS expression vector with pSPAX2 (packaging) and pVSVG (envelope) vectors in the ratio of 3:1:1 into HEK-293T with Turbofect (Fermentas, MD, USA) and thereafter, the cells were culture for an additional 48 hours. The supernatants containing lentiviruses were harvested and filtered through $0.45 \mu \mathrm{m}$ PVDF syringe filter. ORL48 cells expressing high levels of G $\alpha 12$ were seeded at $2 \times 10^{5}$ cell density in 6 -well plates 18 hours prior to lentiviral infection. ORL48 cells were incubated with filtered lentiviral supernatant for 48 hours 
with $10 \mu \mathrm{g} / \mathrm{ml}$ polybrene (Sigma-Aldrich, MO, USA). Virus titre efficiency was evaluated under a fluorescence microscope (Olympus, Japan) to determine the percentage of cells that express GFP. These cells were further sorted by FACS (Beckman Coulter, Fullerton, CA) to harvest only GFP-positive cells and these were further expanded in normal growth medium for down-stream experiments.

\section{Ga12 knockdown by RNA interference}

The pGIPz vectors containing G $\alpha 12$ shRNA target sequences:

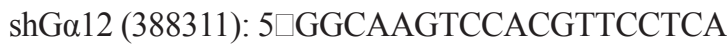
and shG $\alpha 12$ (388313):5 $\square$ GAGACCATCGTCAACAACA3 $\square$ were purchased from Open Biosystems (Thermo Fisher Scientific, AL, USA), and used to knockdown the protein expression of Ga12 in ORL48 cells, essentially following the lentivirus production method as stated above. Viral titration efficiency was evaluated under a fluorescence microscope (Olympus, Japan) to determine the percentage of cells expressing GFP. Transduced cells were selected using $7 \mu \mathrm{g} / \mathrm{ml}$ puromycin (Sigma-Aldrich, MO, USA) and maintained thereafter in medium containing puromycin.

\section{Western blotting}

Cells were lysed on ice in lysis buffer $(0.5 \%$ NaDOC, 0.1\% SDS, 25mM HEPES pH 7.5, 0.3 M NaCl, $1.5 \mathrm{mM} \mathrm{MgCl}, 0.2 \mathrm{mM}$ EDTA, 1\% Triton X-100, 0.5 mM DTT, $20 \mathrm{mM} \beta$-glycerophosphate, $0.1 \mathrm{mM} \mathrm{Na}_{3} \mathrm{VO}_{4}$ ) supplemented with 1x HALT protease inhibitor cocktail (Pierce Biotechnology, IL, USA). Cell lysates were collected after centrifugation at $14000 \mathrm{rpm}$ for 5 minutes at $4^{\circ} \mathrm{C}$. The concentration of total protein in the cell lysate was determined using Bradford protein assay (Pierce Biotechnology, IL, USA). $50 \mu \mathrm{g}$ of total protein was subjected to $12 \%$ SDS-polyacrylamide gel electrophoresis and transferred onto Immobilon-P membrane (Millipore, MA, USA). Blots were blocked with 5\% skimmed milk (TBS with $0.1 \%$ Tween-20) for 1 hour and further incubated with the following primary antibodies: antiGa12 (sc-409; Santa Cruz Biotechnology, CA, USA), anti-Ga13 (sc-410; Santa Cruz Biotechnology, CA, USA) and anti- $\alpha$-tubulin (T9026; Sigma-Aldrich, MO, USA), at a 1:1000 dilution for 1 hour. Blots were washed (x3 for 5 minutes each) in TBS buffer containing $0.1 \%$ Tween-20 (TBS-T) and then probed with respective secondary antibodies conjugated with horseradish peroxidase (dilution 1:10,000; SouthernBiotech, AL, USA) for 1 hour. After washing (TBS-T), detection was performed via enhanced chemiluminescence method, using the ChemiImager $^{\text {TM }}$ Imaging System (Alpha Innotech, USA). Quantification of protein bands was performed using the ImageJ software (http://rsbweb.nih.gov/ij/). The relative intensity of target proteins was calibrated against $\alpha$-tubulin and then compared to the control for each experiment.

\section{RhoA pull-down assay}

RhoA activity in cultured cells was assessed as described by Chikumi and colleagues [49]. Briefly, cells were grown to $70 \%$ confluence in $100 \mathrm{~mm}$ dishes, serumstarved for 18 hours and then stimulated with $1 \mathrm{U} / \mathrm{ml}$ thrombin (Sigma, MO, USA) or $5 \mathrm{uM}$ lysophosphatidic acid (LPA) (Sigma-Aldrich, MO, USA) for 30 seconds to 10 minutes. Cells were lysed on ice with $600 \mu \mathrm{l}$ of cold lysis buffer (detailed above). Lysates were then collected and centrifuged at $14000 \mathrm{rpm}$ for 5 minutes at $4{ }^{\circ} \mathrm{C}$. From the resulting supernatants, $100 \mu \mathrm{l}$ was used for total RhoA protein levels, while the remaining $500 \mu \mathrm{l}$ for each sample were incubated with glutathione-Sepharose 4B beads (GE Healthcare, Sweden) bound to glutathioneS-transferase (GST)-rhotekin-RhoA binding domain for 30 minutes at $4^{\circ} \mathrm{C}$ on a rotator. The beads were collected by centrifugation at $9000 \mathrm{rpm}$ for 1 minute at $4^{\circ} \mathrm{C}$ and washed (x3) with cold lysis buffer. The associated GTPbound RhoA was released with protein loading buffer and denatured by heating for SDS-polyacrylamide gel electrophoresis followed by western blotting. Blots were incubated using anti-RhoA (sc-418; Santa Cruz Biotechnology, CA, USA) at 1:1000 dilution for 1 hour and further processed according to western blotting conditions mentioned above.

\section{Cell proliferation}

Cells were seeded at $2 \times 10^{4}$ density in 6-well plates, and cultured for up to 7 days. Cell counts were performed every 24 hours using the CASY cell counter (Innovatis AG, Reutlingen, Germany), according to manufacturer's instructions. Each experiment was performed in triplicates, and mean cell counts were compared to the respective vector controls across different time intervals.

\section{Scratch assay}

Scratch assays were performed as previously described [50]. In brief, cells were seeded at $4 \times 10^{5}$ cells $/ \mathrm{ml}$ and cultured for 48 hours to form a confluent monolayer. Cells were then treated with $10 \mu \mathrm{g} / \mathrm{ml}$ mitomycin $\mathrm{C}$ for 2 hours to inhibit cell proliferation. A scratch was made through the monolayer with a P200 pipette tip by applying constant pressure to create an open wound. Cells were rinsed with PBS and cultured in DMEM/F-12 complete medium and open wound areas were microscopically recorded between 0 to 18 hours. Images of open wounds were then analyzed using the TScratch analysis software [51].

\section{Transwell migration and matrigel invasion}

Migration assays were performed using 24-well Transwell chambers with polyethylene terephthalate 
(PET) membrane of $8 \mu \mathrm{m}$ pore size (BD Biosciences, MA, USA). Cells were serum-starved for 18 hours and detached with Trypsin-EDTA (Gibco, Auckland, NZ). Then, $1 \times 10^{5}$ cells were suspended in serum-free medium and added to the upper chambers of the Transwell inserts and $3 \mathrm{~T} 3$ cell-conditioned medium or medium containing $1 \mathrm{U} / \mathrm{ml}$ thrombin was used as chemoattractant in the lower chamber. After 48 hours of incubation at $37^{\circ} \mathrm{C}$, cells in the upper surface of the membranes were removed with a cotton swab. The membranes were fixed with $4 \%$ formaldehyde for 15 minutes and stained with $0.2 \%$ crystal violet for 10 minutes, and further rinsed with water. The membranes were detached from the inserts and mounted onto glass slides using DPX mountant. Stained cells were counted in 4 randomly chosen microscopic fields per insert at 200x magnification and average value of 3 biological replicates was obtained.

Cell invasion was assayed with Biocoat Matrigel 24-well invasion chamber (BD Biosciences, MA, USA) according to the method described for the Transwell migration assay, with the exception that inserts were precoated with matrigel basement matrix (BD Biosciences, MA, USA).

\section{Animal studies}

All animal studies were carried out according to National Institutes of Health-approved protocols in compliance with the guide for the care and use of laboratory animals. Female NOD/SCID mice (NCI, Frederick, MD, USA) at 4-6 weeks of age were used in this study. Mice were housed in appropriate sterile filter-capped cages, and fed and watered ad libitum. The orthotopic tongue model was established based on a previous study by Patel and colleagues [22]. Briefly, $1 \times 10^{5}$ ORL48/GFP and ORL48/RGS cells previously sorted for GFP by FACS were injected into the posterior tongue. Mice were evaluated every other day for general behavioral abnormalities, signs of illness or discomfort. Body weights of the animals were recorded and tumor measurements were given visually by the same operator for the duration of the study. Mice were euthanized on day 20 and the neck area of each mouse was carefully dissected under a Discovery V12 Stereo microscope (Zeiss, Thornwood NY, USA) to retrieve 4 to 5 cervical lymph nodes. Next, the tongues for each mouse in each group were resected. The resected tissues were fixed in formalin overnight and then transferred to $70 \%$ alcohol and processed for paraffin embedding for histopathological evaluation by a pathologist (AAM). H\&E-stained slides from primary tumors were acquired with an Aperio CS Scanscope (Aperio, Vista, CA, USA) at 40x magnification. Tumor volume was determined using the formula: $\mathrm{LW}^{2} / 2$; where $\mathrm{L}$ and $\mathrm{W}$ represent length and the width of the tumor respectively.

\section{Statistical analyses}

Statistical analyses were performed using SPSS 16 (SPSS Inc., Chicago, IL, USA) software. Ga12 mRNA levels in OSCC and NOM tissues were compared using the Mann-Whitney $U$ test. The receiver operating characteristic (ROC) curve was used to determine the cut-off point for the IHC scoring of Ga12 expression in differentiating the tumors from the NOM tissues. Fisher-exact test was used to study the association between Ga12 protein expression in OSCC and various clinicopathological parameters. Independent t-test was used to analyze the differences in in vitro cell proliferation, invasion and migration, as well as in in vivo experiments comparing the tumor volume and LN involvement between the two groups of animals.

\section{ACKNOWLEDGEMENT}

This study was funded by UICC (ICRETT), MOSTI (06-00-00-0000), UM.C/625/1/HIR/MOHE/ DENT-03 and other supporters of CARIF. CARIF is a non-profit research organization. We are committed to an understanding of cancer prevention, diagnosis and treatment through a fundamental research program. The authors would like to thank Susan Hoe (Institute for Medical Research, Malaysia) for technical assistance with the cell sorter.

\section{REFERENCES}

1. Chambers AF, Groom AC, MacDonald IC. Dissemination and growth of cancer cells in metastatic sites. Nat Rev Cancer. 2002; 2:563-572.

2. Houck JR, Medina JE. Management of cervical lymph nodes in squamous carcinomas of the head and neck. Semin Surg Oncol. 1995; 11:228-239.

3. Tankere F, Camproux A, Barry B, Guedon C, Depondt J, Gehanno P. Prognostic value of lymph node involvement in oral cancers: a study of 137 cases. Laryngoscope. 2000; 110:2061-2065.

4. Kalnins IK, Leonard AG, Sako K, Razack MS, Shedd DP. Correlation between prognosis and degree of lymph node involvement in carcinoma of the oral cavity. Am J Surg. $1977 ; 134: 450-454$.

5. Zanaruddin SN, Saleh A, Yang YH, Hamid S, Mustafa WM, Khairul Bariah AA, Zain RB, Lau SH, Cheong SC. Four-protein signature accurately predicts lymph node metastasis and survival in oral squamous cell carcinoma. Hum Pathol. 2013; 44:417-426.

6. Strathmann MP, Simon MI. G alpha 12 and G alpha 13 subunits define a fourth class of $\mathrm{G}$ protein alpha subunits. Proc Natl Acad Sci U S A. 1991; 88:5582-5586. 
7. Ruppel KM, Willison D, Kataoka H, Wang A, Zheng YW, Cornelissen I, Yin L, Xu SM, Coughlin SR. Essential role for Galpha13 in endothelial cells during embryonic development. Proc Natl Acad Sci U S A. 2005; 102:82818286.

8. Parks S, Wieschaus E. The Drosophila gastrulation gene concertina encodes a $\mathrm{G}$ alpha-like protein. Cell. 1991; 64:447-458.

9. Lin F, Sepich DS, Chen S, Topczewski J, Yin C, Solnica-Krezel L, Hamm H. Essential roles of $\mathrm{G}\{$ alpha $\} 12 / 13$ signaling in distinct cell behaviors driving zebrafish convergence and extension gastrulation movements. J Cell Biol. 2005; 169:777-787.

10. Moers A, Nieswandt B, Massberg S, Wettschureck N, Gruner S, Konrad I, Schulte V, Aktas B, Gratacap MP, Simon MI, Gawaz M, Offermanns S. G13 is an essential mediator of platelet activation in hemostasis and thrombosis. Nat Med. 2003; 9:1418-1422.

11. Offermanns $\mathrm{S}, \mathrm{Hu} \mathrm{YH}$, Simon MI. Galpha12 and galpha13 are phosphorylated during platelet activation. J Biol Chem. 1996; 271:26044-26048.

12. Offermanns S, Mancino V, Revel JP, Simon MI. Vascular system defects and impaired cell chemokinesis as a result of Galpha13 deficiency. Science. 1997; 275:533-536.

13. Berestetskaya YV, Faure MP, Ichijo H, VoynoYasenetskaya TA. Regulation of apoptosis by alphasubunits of G12 and G13 proteins via apoptosis signalregulating kinase-1. J Biol Chem. 1998; 273:27816-27823.

14. Chan AM, Fleming TP, McGovern ES, Chedid M, Miki T, Aaronson SA. Expression cDNA cloning of a transforming gene encoding the wild-type $\mathrm{G}$ alpha 12 gene product. Mol Cell Biol. 1993; 13:762-768.

15. Xu N, Bradley L, Ambdukar I, Gutkind JS. A mutant alpha subunit of G12 potentiates the eicosanoid pathway and is highly oncogenic in NIH 3 T3 cells. Proc Natl Acad Sci U S A. 1993; 90:6741-6745.

16. Kelly P, Moeller BJ, Juneja J, Booden MA, Der CJ, Daaka Y, Dewhirst MW, Fields TA, Casey PJ. The G12 family of heterotrimeric $\mathrm{G}$ proteins promotes breast cancer invasion and metastasis. Proc Natl Acad Sci U S A. 2006; 103:8173-8178.

17. Kelly P, Stemmle LN, Madden JF, Fields TA, Daaka Y, Casey PJ. A role for the G12 family of heterotrimeric G proteins in prostate cancer invasion. J Biol Chem. 2006; 281:26483-26490.

18. Liu SC, Jen YM, Jiang SS, Chang JL, Hsiung CA, Wang $\mathrm{CH}$, Juang JL. G(alpha)12-mediated pathway promotes invasiveness of nasopharyngeal carcinoma by modulating actin cytoskeleton reorganization. Cancer Res. 2009; 69:6122-6130.

19. Yagi H, Tan W, Dillenburg-Pilla P, Armando S, Amornphimoltham P, Simaan M, Weigert R, Molinolo AA,
Bouvier M, Gutkind JS. A synthetic biology approach reveals a CXCR4-G13-Rho signaling axis driving transendothelial migration of metastatic breast cancer cells. Sci Signal. 2011; 4:ra60.

20. Cheong SC, Chandramouli GV, Saleh A, Zain RB, Lau SH, Sivakumaren S, Pathmanathan R, Prime SS, Teo SH, Patel V, Gutkind JS. Gene expression in human oral squamous cell carcinoma is influenced by risk factor exposure. Oral Oncol. 2009; 45:712-719.

21. Fukuhara S, Chikumi H, Gutkind JS. RGS-containing RhoGEFs: the missing link between transforming $G$ proteins and Rho? Oncogene. 2001; 20:1661-1668.

22. Patel V, Marsh CA, Dorsam RT, Mikelis CM, Masedunskas A, Amornphimoltham P, Nathan CA, Singh B, Weigert R, Molinolo AA, Gutkind JS. Decreased lymphangiogenesis and lymph node metastasis by mTOR inhibition in head and neck cancer. Cancer Res. 2011; 71:7103-7112.

23. Woolgar JA. Detailed topography of cervical lymph-note metastases from oral squamous cell carcinoma. Int J Oral Maxillofac Surg. 1997; 26:3-9.

24. Spicher K, Kalkbrenner F, Zobel A, Harhammer R, Nurnberg B, Soling A, Schultz G. G12 and G13 alphasubunits are immunochemically detectable in most membranes of various mammalian cells and tissues. Biochem Biophys Res Commun. 1994; 198:906-914.

25. O’Hayre M, Vazquez-Prado J, Kufareva I, Stawiski EW, Handel TM, Seshagiri S, Gutkind JS. The emerging mutational landscape of $\mathrm{G}$ proteins and G-protein-coupled receptors in cancer. Nat Rev Cancer. 2013; 13:412-424.

26. Stransky N, Egloff AM, Tward AD, Kostic AD, Cibulskis K, Sivachenko A, Kryukov GV, Lawrence MS, Sougnez C, McKenna A, Shefler E, Ramos AH, Stojanov P, Carter SL, Voet D, Cortes ML. The mutational landscape of head and neck squamous cell carcinoma. Science. 2011; 333:1157-1160.

27. Cardenas-Navia LI, Cruz P, Lin JC, Rosenberg SA, Samuels Y. Novel somatic mutations in heterotrimeric $\mathrm{G}$ proteins in melanoma. Cancer Biol Ther. 2010; 10:33-37.

28. Bian D, Mahanivong C, Yu J, Frisch SM, Pan ZK, Ye RD, Huang S. The G12/13-RhoA signaling pathway contributes to efficient lysophosphatidic acid-stimulated cell migration. Oncogene. 2006; 25:2234-2244.

29. Dorsam RT, Gutkind JS. G-protein-coupled receptors and cancer. Nat Rev Cancer. 2007; 7:79-94.

30. Jiang $\mathrm{H}, \mathrm{Wu} \mathrm{D}$, Simon MI. The transforming activity of activated G alpha 12. FEBS Lett. 1993; 330:319-322.

31. Althoefer H, Eversole-Cire P, Simon MI. Constitutively active Galphaq and Galpha13 trigger apoptosis through different pathways. J Biol Chem. 1997; 272:2438024386. 
32. Jian SL, Hsieh HY, Liao CT, Yen TC, Nien SW, Cheng AJ, Juang JL. Galpha(1)(2) drives invasion of oral squamous cell carcinoma through up-regulation of proinflammatory cytokines. PLoS One. 2013; 8:e66133.

33. Takashima S, Sugimoto N, Takuwa N, Okamoto Y, Yoshioka K, Takamura M, Takata S, Kaneko S, Takuwa Y. G12/13 and Gq mediate S1P2-induced inhibition of Rac and migration in vascular smooth muscle in a manner dependent on Rho but not Rho kinase. Cardiovasc Res. 2008; 79: 689-697.

34. Tan W, Martin D, Gutkind JS. The Galpha13-Rho signaling axis is required for SDF-1-induced migration through CXCR4. J Biol Chem. 2006; 281:39542-39549.

35. Xu J, Wang F, Van Keymeulen A, Herzmark P, Straight A, Kelly K, Takuwa Y, Sugimoto N, Mitchison T, Bourne HR. Divergent signals and cytoskeletal assemblies regulate self-organizing polarity in neutrophils. Cell. 2003; 114:201-214.

36. Rieken S, Sassmann A, Herroeder S, Wallenwein B, Moers A, Offermanns S, Wettschureck N. G12/G13 family $\mathrm{G}$ proteins regulate marginal zone $\mathrm{B}$ cell maturation, migration, and polarization. J Immunol. 2006; 177: 2985-2993.

37. Fromm C, Coso OA, Montaner S, Xu N, Gutkind JS. The small GTP-binding protein Rho links G protein-coupled receptors and Galpha12 to the serum response element and to cellular transformation. Proc Natl Acad Sci U S A. 1997; 94:10098-10103.

38. Gavard J, Gutkind JS. Protein kinase C-related kinase and ROCK are required for thrombin-induced endothelial cell permeability downstream from Galpha12/13 and Galpha11/q. J Biol Chem. 2008; 283:29888-29896.

39. Riobo NA, Manning DR. Receptors coupled to heterotrimeric $G$ proteins of the G12 family. Trends Pharmacol Sci. 2005; 26:146-154.

40. Gong H, Shen B, Flevaris P, Chow C, Lam SC, Voyno-Yasenetskaya TA, Kozasa T, Du X. G protein subunit Galpha13 binds to integrin alphaIIbbeta3 and mediates integrin "outside-in" signaling. Science. 2010; 327:340-343.

41. Meigs TE, Fields TA, McKee DD, Casey PJ. Interaction of Galpha 12 and Galpha 13 with the cytoplasmic domain of cadherin provides a mechanism for beta-catenin release. Proc Natl Acad Sci U S A. 2001; 98:519-524.

42. Malhotra R, Patel V, Chikkaveeraiah BV, Munge BS, Cheong SC, Zain RB, Abraham MT, Dey DK, Gutkind JS, Rusling JF. Ultrasensitive detection of cancer biomarkers in the clinic by use of a nanostructured microfluidic array. Anal Chem. 2012; 84:6249-6255.

43. Voyno-Yasenetskaya TA, Pace AM, Bourne HR. Mutant alpha subunits of G12 and G13 proteins induce neoplastic transformation of Rat-1 fibroblasts. Oncogene. 1994; 9:2559-2565.

44. Grzelinski M, Pinkenburg O, Buch T, Gold M, Stohr S, Kalwa H, Gudermann T, Aigner A. Critical role of G(alpha)12 and G(alpha)13 for human small cell lung cancer cell proliferation in vitro and tumor growth in vivo. Clin Cancer Res. 2010; 16:1402-1415.

45. Roepman P, Wessels LF, Kettelarij N, Kemmeren P, Miles AJ, Lijnzaad P, Tilanus MG, Koole R, Hordijk GJ, van der Vliet PC, Reinders MJ, Slootweg PJ, Holstege FC. An expression profile for diagnosis of lymph node metastases from primary head and neck squamous cell carcinomas. Nat Genet. 2005; 37:182-186.

46. Zain RB, Ghani WM, Razak IA, Latifah RJ, Samsuddin AR, Cheong SC, Abdullah N, Ismail AR, Hussaini HB, Talib NA, Jallaludin A. Building partnership in oral cancer research in a developing country: processes and barriers. Asian Pac J Cancer Prev. 2009; 10:513-518.

47. Hamid S, Lim KP, Zain RB, Ismail SM, Lau SH, Mustafa WM, Abraham MT, Nam NA, Teo SH, Cheong SC. Establishment and characterization of Asian oral cancer cell lines as in vitro models to study a disease prevalent in Asia. Int J Mol Med. 2007; 19:453-460.

48. Basile JR, Barac A, Zhu T, Guan KL, Gutkind JS. Class IV semaphorins promote angiogenesis by stimulating Rhoinitiated pathways through plexin-B. Cancer Res. 2004; 64:5212-5224.

49. Chikumi H, Vazquez-Prado J, Servitja JM, Miyazaki H, Gutkind JS. Potent activation of RhoA by Galpha q and Gq-coupled receptors. J Biol Chem. 2002; 277:27130 27134.

50. Chong CE, Lim KP, Gan CP, Marsh CA, Zain RB, Abraham MT, Prime SS, Teo SH, Silvio Gutkind J, Patel V, Cheong SC. Over-expression of MAGED4B increases cell migration and growth in oral squamous cell carcinoma and is associated with poor disease outcome. Cancer Lett. 2012; 321:18-26.

51. Geback T, Schulz MM, Koumoutsakos P, Detmar M. TScratch: a novel and simple software tool for automated analysis of monolayer wound healing assays. Biotechniques. 2009; 46:265-274. 